\title{
INVESTIGATION OF TRANSIENT PERFORMANCE OF CAPACITOR VOLTAGE TRANSFORMER (CVT)
}

(Date received: 19.2 .2008$)$

\author{
Associated Prof. Dr Saad Mekhilef', Mr. Cheng Hock Lim² and Dr Ab. Halim Abu Bakar ${ }^{3}$ \\ ${ }^{1,2,3}$ Department of Electrical Engineering, \\ University of Malaya, 50603 UM, Kuala Lumpur \\ E-mail:saad@um.edu.my. ${ }^{1}$
}

\begin{abstract}
This paper reports the digital-time domain studies on a typical 132kV Capacitor Voltage Transformer (CVT) model. The transient studies are conducted using Alternative Transient Program (ATP-EMTP). Simulation results corresponding to the CVT transient response under both system fault and ferroresonance condition are reported in this paper. Transient studies are performed (1) to identify the CVT components that contribute to the transient response of CVT, (2) to determine system condition that affect the CVT transient response. A lightning simulation case study is also presented to demonstrate the ferroresonance oscillation sustained inside a CVT due to lightning strike as affected by the factors of lightning current amplitude and distance between CVT and lightning arrester.
\end{abstract}

Keywords: ATP-EMTP, CVT and Ferroresonance

\subsection{INTRODUCTION}

Capacitive Voltage Transformers (CVTs) are the predominant source of voltage signals for monitoring, protection relays and control application at transmission and subtransmission voltage level. For the past few years, electric utility in Malaysia has reported a big number of CVT failures and explosions in the substations. These have affected the reliability of the power system [1-4].

Theoretically, the output waveform of a CVT should be an exact replica of the input waveform under all operating system conditions [5-8]. This requirement can easily be satisfied under steady-state condition. However, electric power systems are subjected to many types of disturbances that results in electric transients due to lightning, system fault, line energization and deenergisation, switching of inductive or capacitive load. Under such transient conditions, the CVT output waveform may not follow closely to its input waveform due to internal storage elements such as capacitive, inductive and non-linear components (saturable magnetic core) of the CVT [9-12]. They take time to dissipate their stored energy. Electromechanical relays can cope with unfavorable CVT transients due to their natural mechanical inertia at the expense of slower operation. Digital relays are designed for high-speed tripping and therefore they face certain CVT related transient problem [13-15].

The phenomenon of ferroresonance is of particular concern during CVT transients because it may cause thermal overstress and consequently deterioration of CVT components due to transient overvoltages produced inside the CVT. The transient errors produced can have major impact on the dependability and security of the protective relay which may affect the overall protection performance [16].
In order to have a better access to the above issues, a thorough investigation of the CVT transient performance is needed. In this work, a typical $132 \mathrm{kV}$ CVT model to be used in connection with the ATP-EMTP is presented. Digital time domain simulations corresponding to system fault and ferroresonance condition are carried out. The objectives of this work are (1) to identify the CVT transients' contribution factors, and (2) to investigate the impact of power system transient e.g. system faults and lightning on the transient performance of CVT [17-19].

Lightning stroke near the high voltage (H.V.) transmission line is one of the most common transient disturbances found in high voltage substation. The transient disturbances always transmitted through instrument transformer to the complex and distributed protection circuit, connected at their secondary terminals and seriously affect their workings [20-23]. To realise the above problem, a lightning case study was carried out to investigate the ferroresonance oscillations sustained inside a CVT, which are of serious concern, predominantly because of causing possible damage to CVT.

\subsection{CVT MODEL}

Figure 1 shows the circuit diagram of the typical $132 \mathrm{kV}$ CVT model used for the studies. Switches S1 and S2 are not part of the CVT circuitry, it's included in the model to simulate various transient scenarios imposed on the CVT.

Basically, the CVT model is composed of Capacitive Voltage Divider (C1 and C2), Step-down Transformer (SDT), Compensating Series Reactor (SR), Ferroresonance Suppression Circuit (Cf, Rf, Lf), and Overvoltage Protection devices (Vgap, Rgap). 


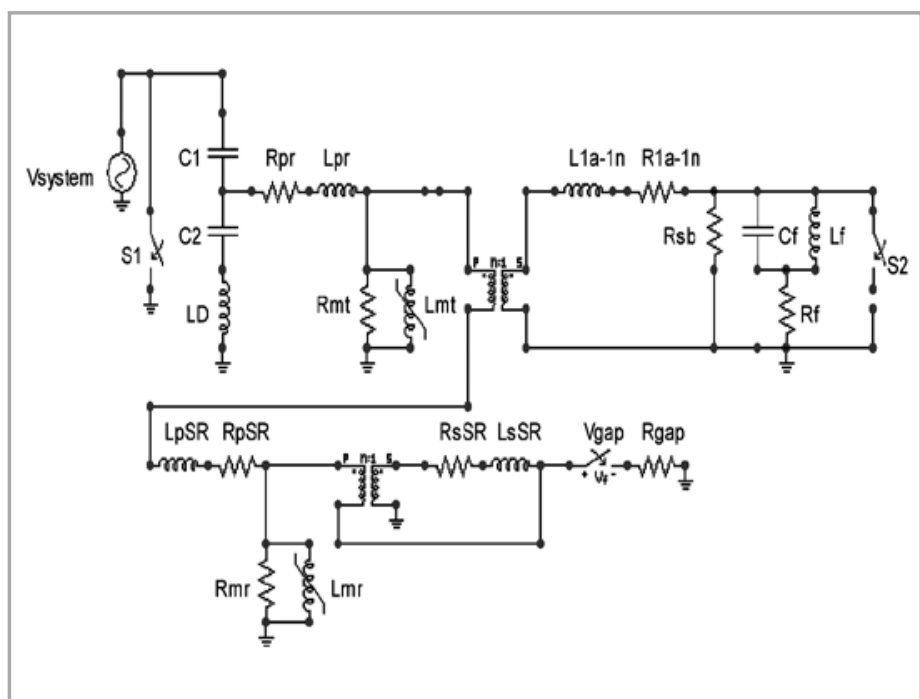

Figure $1:$ CVT circuit diagram

It should be noted that Vgap represents either a spark gap with pre-specified break-down voltage or voltage-controlled switch which is triggered at a pre-specified voltage level. This CVT model utilises a voltage-controlled switched as available in ATPDraw. The voltage-controlled switch is open originally, and tries to close after $\mathrm{T} \geq \mathrm{T}$ close. The closing is successful as soon as the voltage across the switch is $\geq$ Flashover Voltage. After the switch has closed, it will wait until the time delay Tdelay has elapsed and then tries to open again.

\subsection{DIGITAL TIME DOMAIN STUDIES}

Digital time domain simulations corresponding to ferroresonance tests (short-circuit across secondary winding) and system fault are conducted on the CVT model to investigate the transient contribution factor.

\subsection{FERRORESONANCE TESTS}

To investigate the transient response contribution factors under ferroresonance condition, short-circuit across secondary winding is imposed by closing S2 at peak voltage and then opening S2 after $1 \mathrm{sec}$. The tests are carried out under different cases to investigate the effect of CVT components, and system condition on the ferroresonance response.

\section{Case 1: CVT Burden}

This case investigates the effect CVT burden (system condition) on the CVT ferroresonance phenomena. CVT burden is one of the dissipating paths for energy accumulated in the CVT circuitry. Its effect is so profound that it can dominate the CVT transient behavior. The tests make use of two types of burdens as suggested by [3] for transient response test as follow:

(i) Pure Resisitive Burden

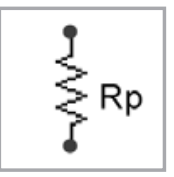

(ii) Series Burden

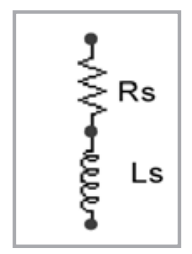

Figure 2(a) shows the CVT output response is subjected to ferroresonance oscillation after the secondary short circuit is cleared (no load is connected). The ferroresonance is cleared after nearly 10 cycles. Figures 2(b) and 2(c) show the CVT response to ferroresonance test when pure resisitive burden of 100VA and 400VA is included on the secondary winding of the CVT as load respectively. Figure 2(b) shows that the ferroresonance is cleared after nearly 7 cycles. Whereas, Figure 2(c) shows that the ferroresonance is cleared after 2 cycles. These indicate that, the ferroresonance can be more effectively damped out when we have load with higher VA. Therefore it is recommended that the CVT be fully loaded to avoid extensive transient.

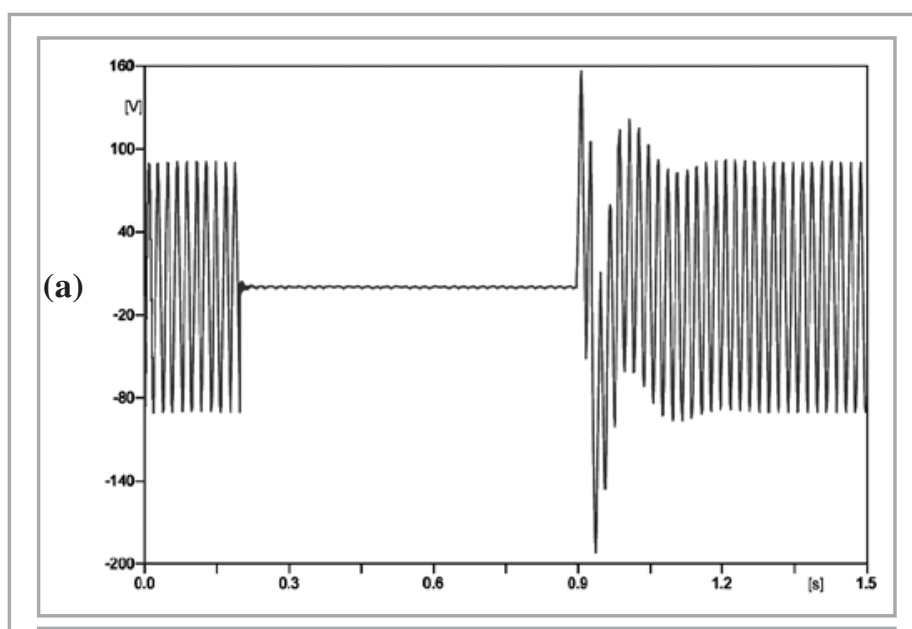

(b)
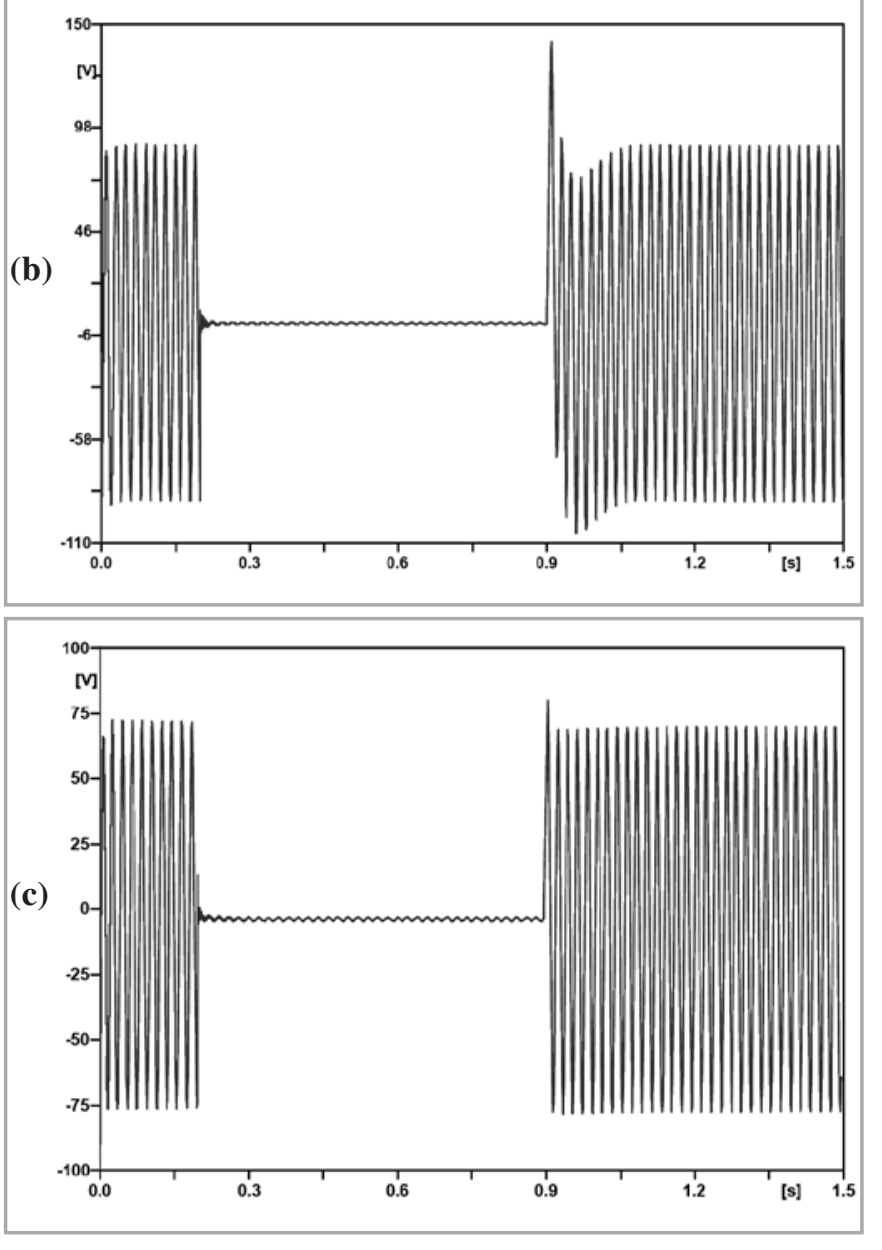

Figure 2 : CVT output voltage response to ferroresonance test for pure resistive burden (a) burden $=0, \mathrm{VA}$ (b) burden $=100 \mathrm{VA}(\mathrm{c})$ burden $=400 \mathrm{VA}$ 
Figures 3(a) and 3(b) show the CVT response to ferroresonance test when series burden with power factor of 0.2 and 0.8 is included on the secondary winding of the CVT as load respectively. By comparing both figures, it is obvious that ferroresonance is more effectively damped out for load with higher power factor. Hence, it is fair to say that higher power factor burden gives better transient response.
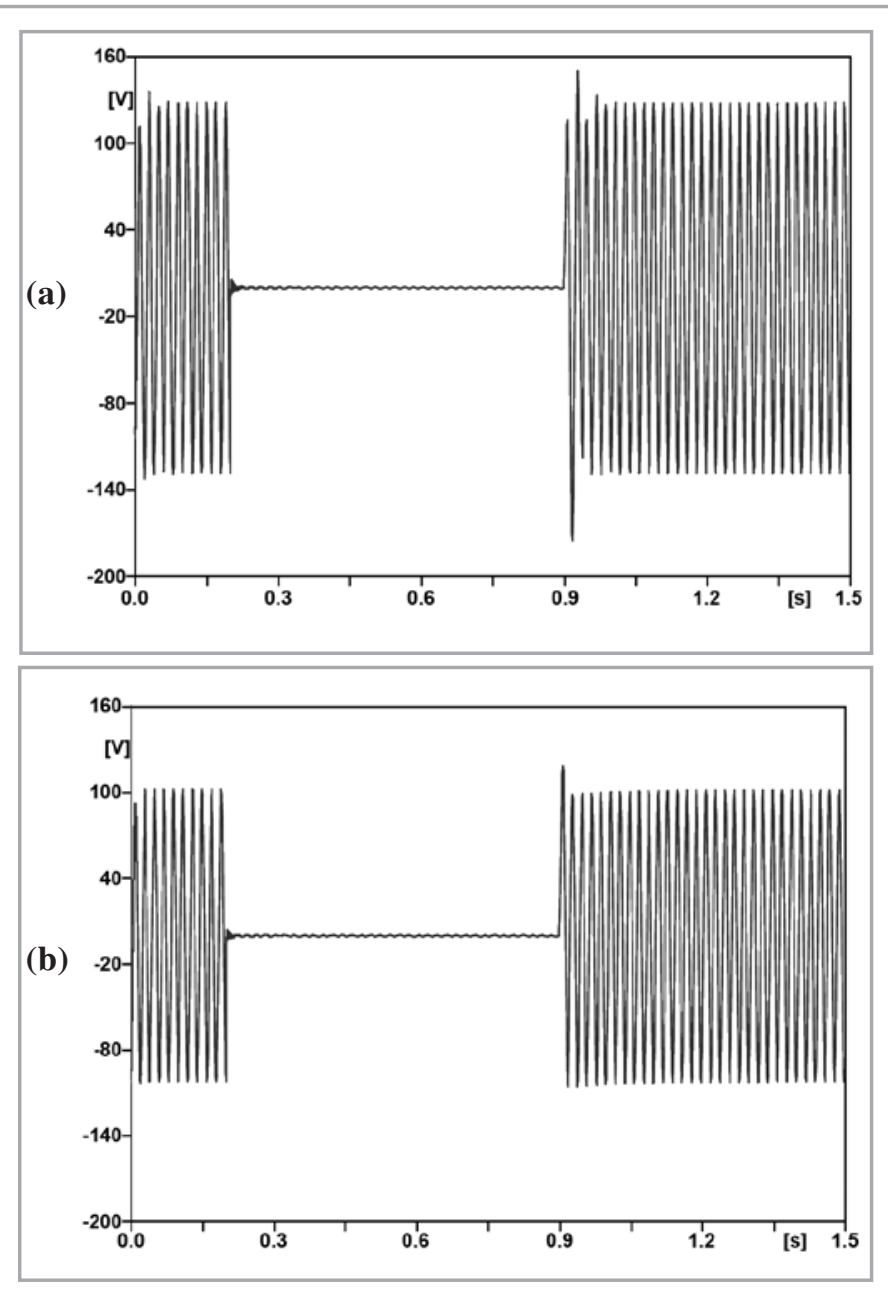

Figure 3 : CVT output voltage response to ferroresonance test for series burden of 200VA (a) power factor $=0.2$, and $(b)$ power factor $=0.8$.

\section{Case 2: Ferroresonance Suppression Circuit}

This case investigates the effect of ferroresonance suppression circuit (FSC) on the CVT transient performance. FSC is designed to avoid dangerous and destructive overvoltages caused by ferroresonance. It loads a CVT and creates an extra path- apart from the burden - for dissipating energy. A specific design of FSC is often treated as proprietary information and is seldom available. However, two generic models of FSC that are commonly used in CVT will be considered here. They are the active ferroresonance circuit (ASFC) and passive ferroresonance circuit (PFSC) as shown in Figures 4(a) and 4(b) respectively.

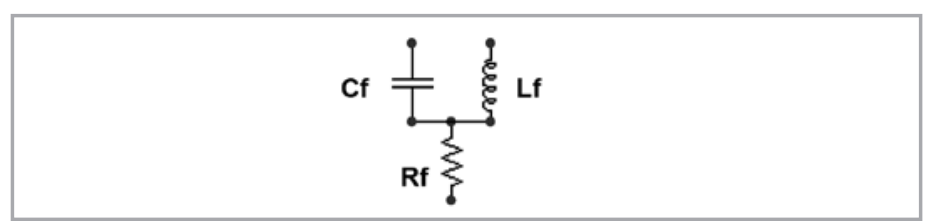

Figure 4(a) : Active ferroresonance suppression circuit

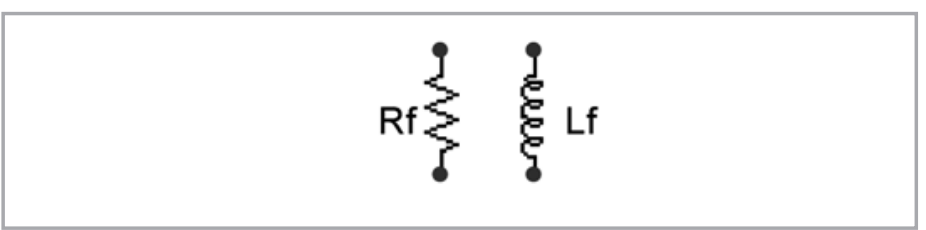

Figure 4(b) : Passive ferroresonance suppression circuit

Figures 5(a) and 5(b) show the transient response of the CVT with AFSC and CVT with PSFC respectively. Note that the CVT with a PFSC has a better, less distorted transient response (lower voltage spike) as compare CVT with an AFSC.
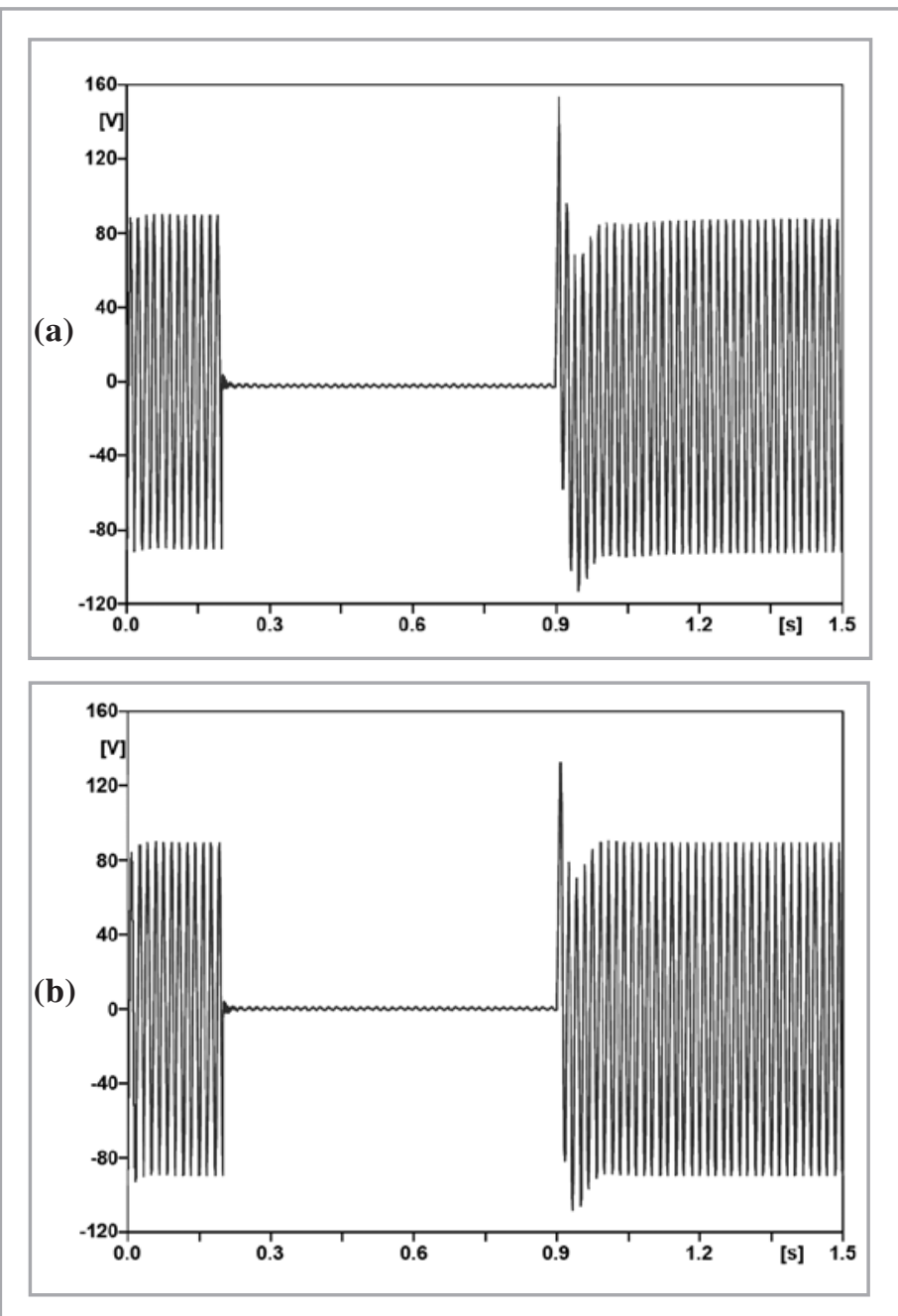

Figure 5 : CVT output voltage responses for (a) CVT with AFSC and (b) CVT with PSFC

\subsection{SYSTEM FAULT}

A simplified equivalent circuit of the CVT model as shown in Figure 6 is used to investigate the transient response contribution factors during a close-in, line-to-ground fault using ATPDraw simulation. This is imposed by closing and opening switch S1. The tests are carried out under different cases to investigate the effect of CVT components, and system condition on the CVT transient response.

\section{Case 1: Sum of Stack Capacitance}

This case investigates the effect of the sum of stack capacitance, (CVT component) on the CVT transient performance.

Journal - The Institution of Engineers, Malaysia (Vol. 71, No.2, June 2009) 


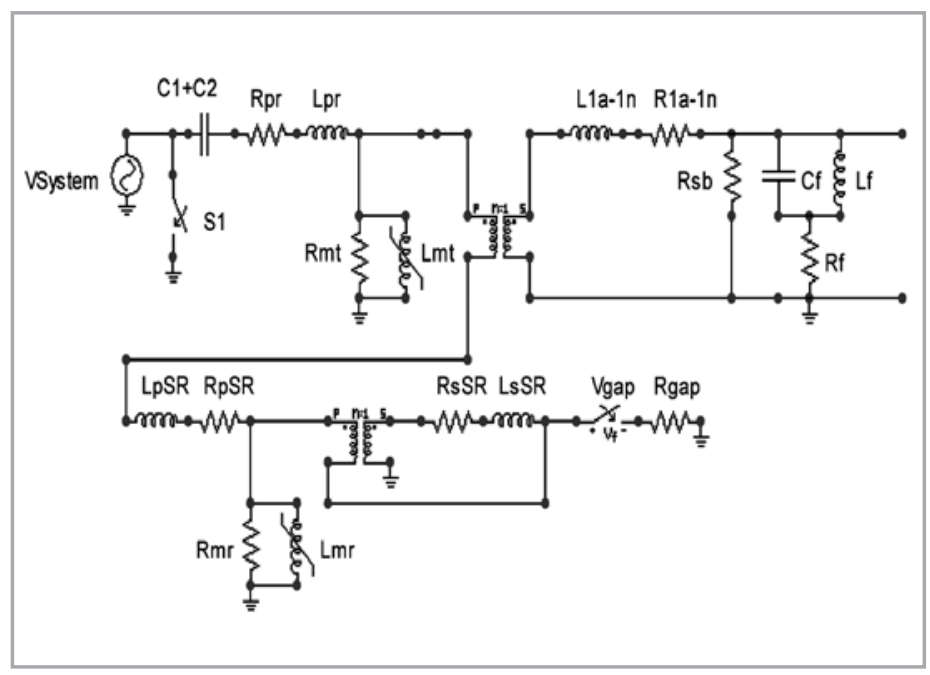

Figure 6: Simplified equivalent circuit of the CVT model

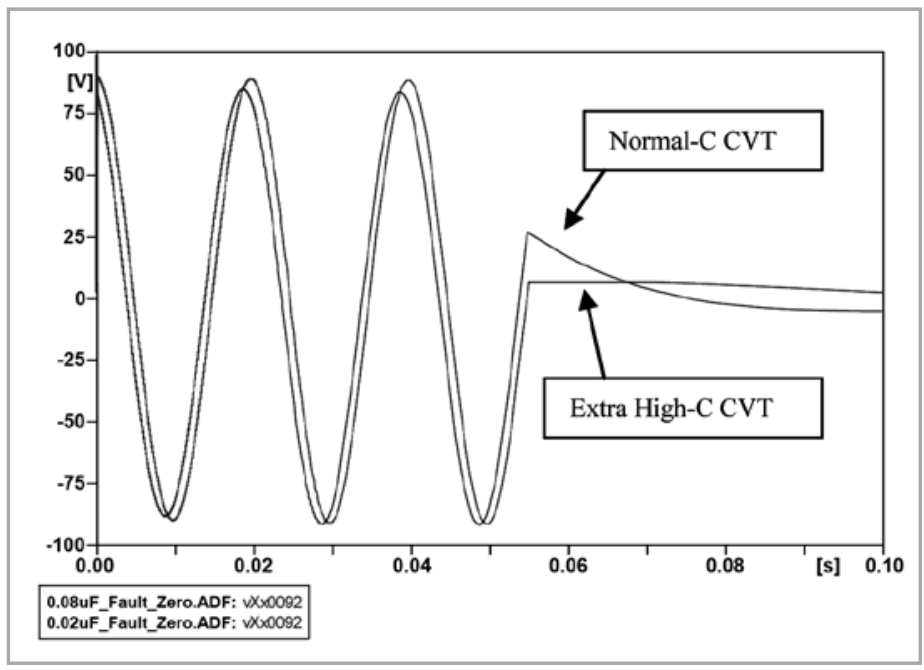

Figure 7: CVT otuput voltage

Figure 7 shows the CVT output voltages for both CVT with normal-Capacitance and Extra-High Capacitance respectively. Note that the higher the sum of stack capacitance, the lower the magnitude of the transients.

\section{Case 2: Point on Wave when Fault Occur}

This case investigates the effect of point on wave when fault occur (system condition) on CVT transient.

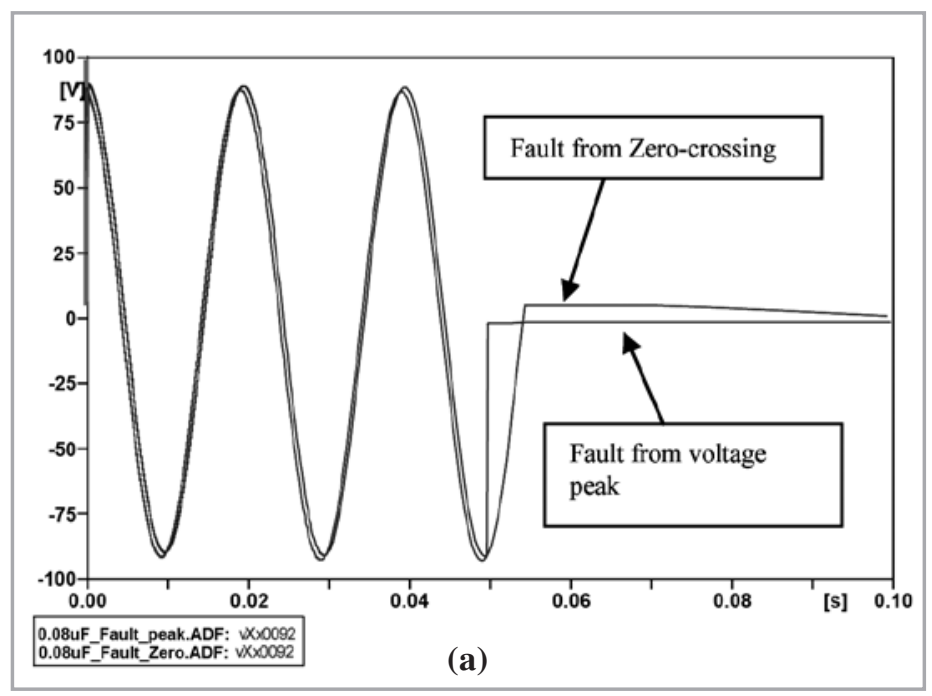

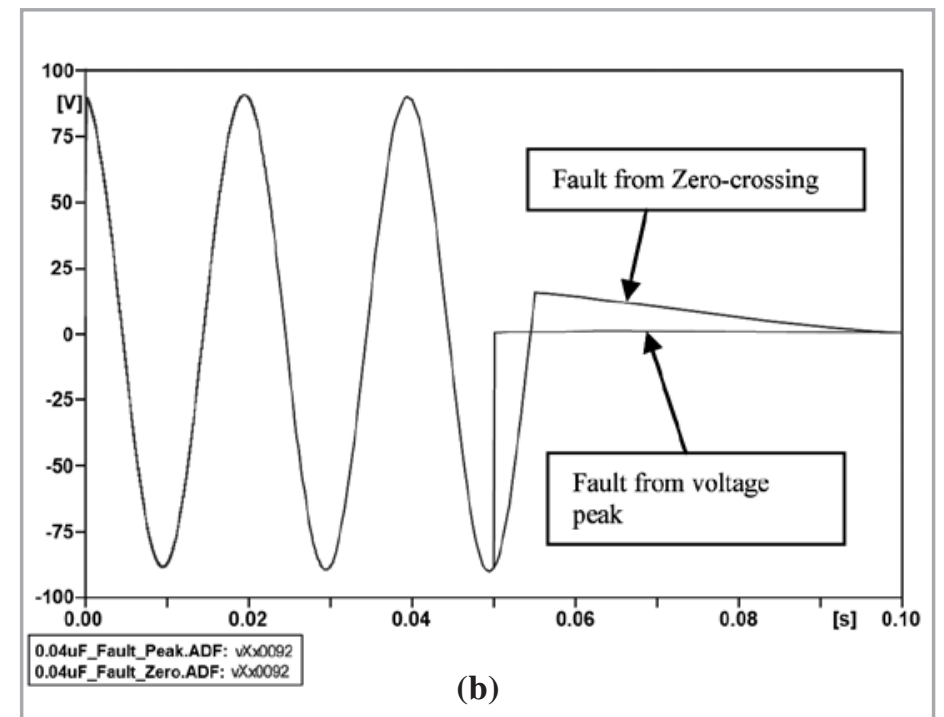

Figure 8 : CVT Secondary output voltage for (a) Extra-High-C CVT and (b) High-C CVT

Figures 8(a) and 8(b) show the extra-high-C CVT and high-C CVT secondary output voltages for system fault occur at both voltage peak and zero crossing respectively. It clearly shows that most severe transients are generated when a fault occur at the zero crossing of the primary voltage.

\subsection{LIGHTNING SIMULATION}

Lightning surge analysis is performed on a typical power system configuration in which the CVT model is connected. The lightning source is represented in this study by a single-stroke Heidler-type current source model, with parallel impedance equal to the lightning channel surge impedance. Lightning arrester is modeled using Metal-Oxide Surge arrester. Two different case studies are conducted to investigate the important factors, which affect the CVT transient when a typical power system configuration is subjected to lightning strike. These factors include the lightning current amplitude, and distance between CVT and lightning arrester.

\section{Case 1: Lightning Current Amplitude}

Figure 9 shows the CVT secondary output voltages when lightning current is injected at different peak current setting. Each stroke is a triangular current impulse of 1.5/50 $\mu$ s.

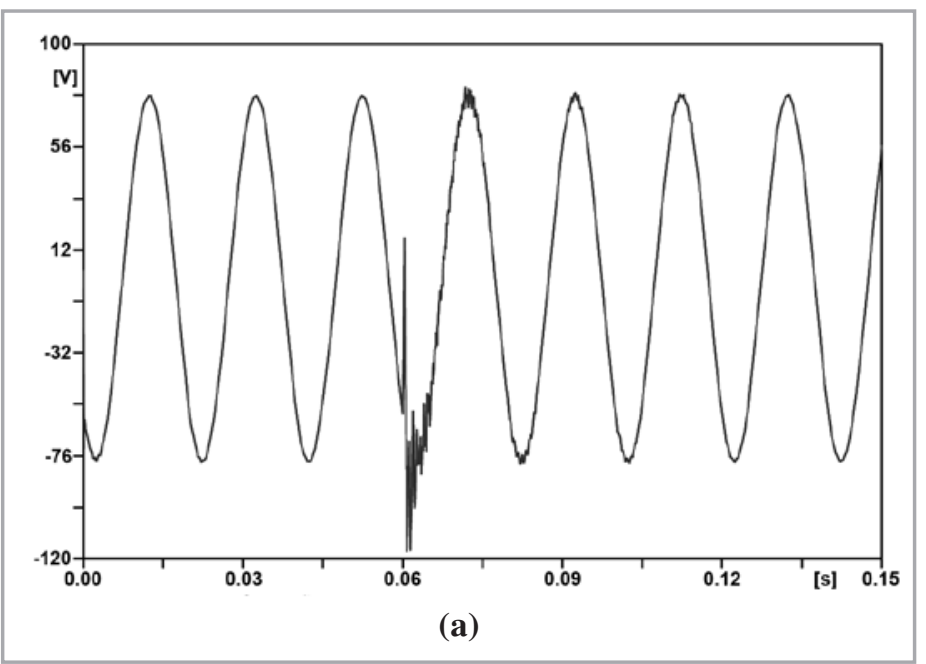




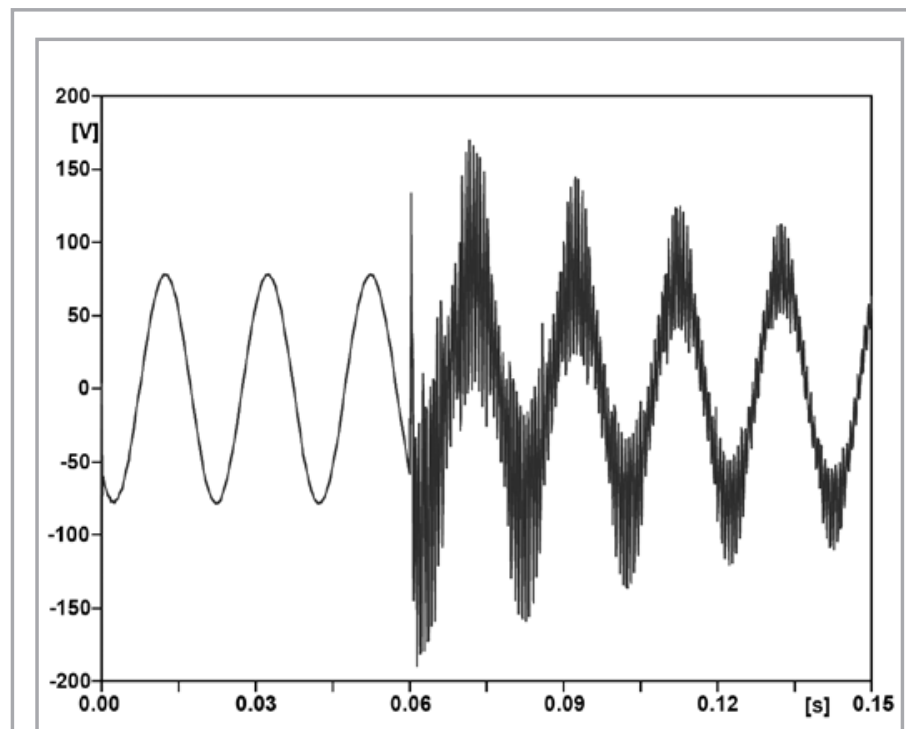

(b)

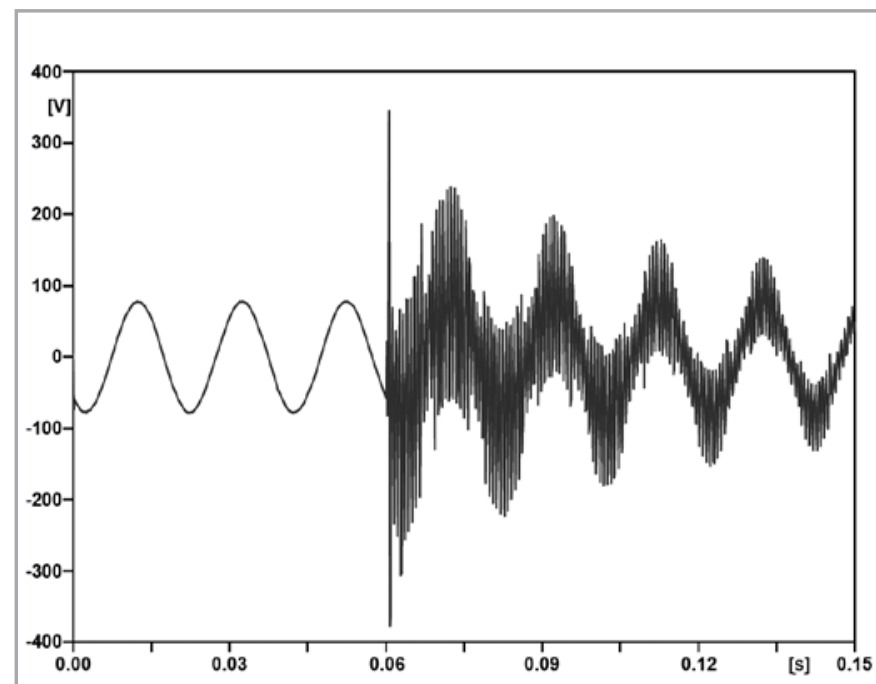

(c)

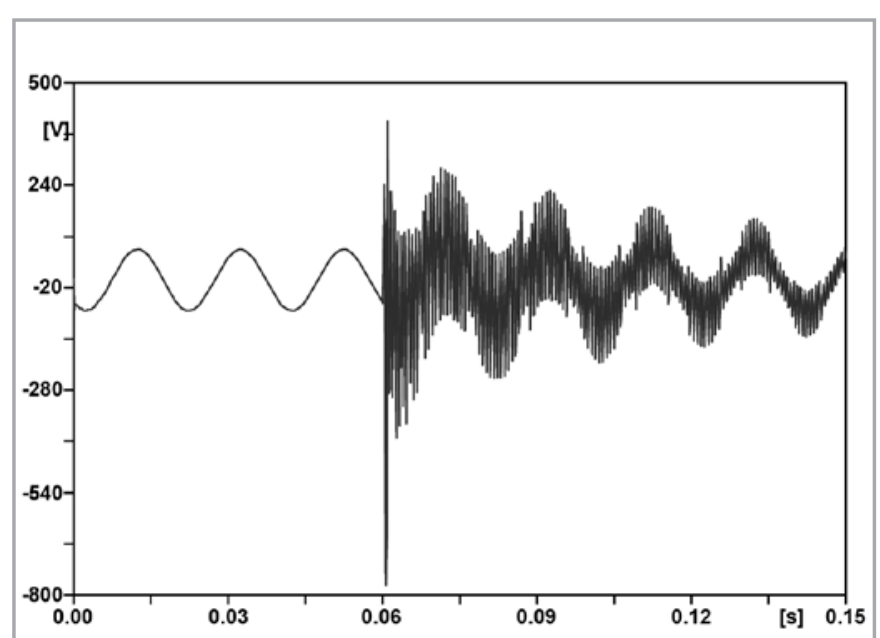

(d)

Figure 9 CVT secondary voltages for (a) lightning peak Current = $4000 A$, (b) lightning peak current $=20000 A$, (c) Lightning peak current $=34500 \mathrm{~A}$, and $(d)$ Lightning peak current $=200000 \mathrm{~A}$.
Figure 9(a) through (d) clearly show that lightning surge can cause ferroresonance oscillation in CVT. The oscillation becomes worse as the lightning peak current increase, involving frequencies higher than the operating frequency of the system. This can lead to heating of transformer. High temperatures inside the transformer may weaken the insulation and cause failure under electrical stress.

\section{Case 2: Distance between Lightning Arrester and CVT}

Figure 10(a) and 10(b) show the CVT secondary output voltages for two different distances between the lightning arrester and the CVT.
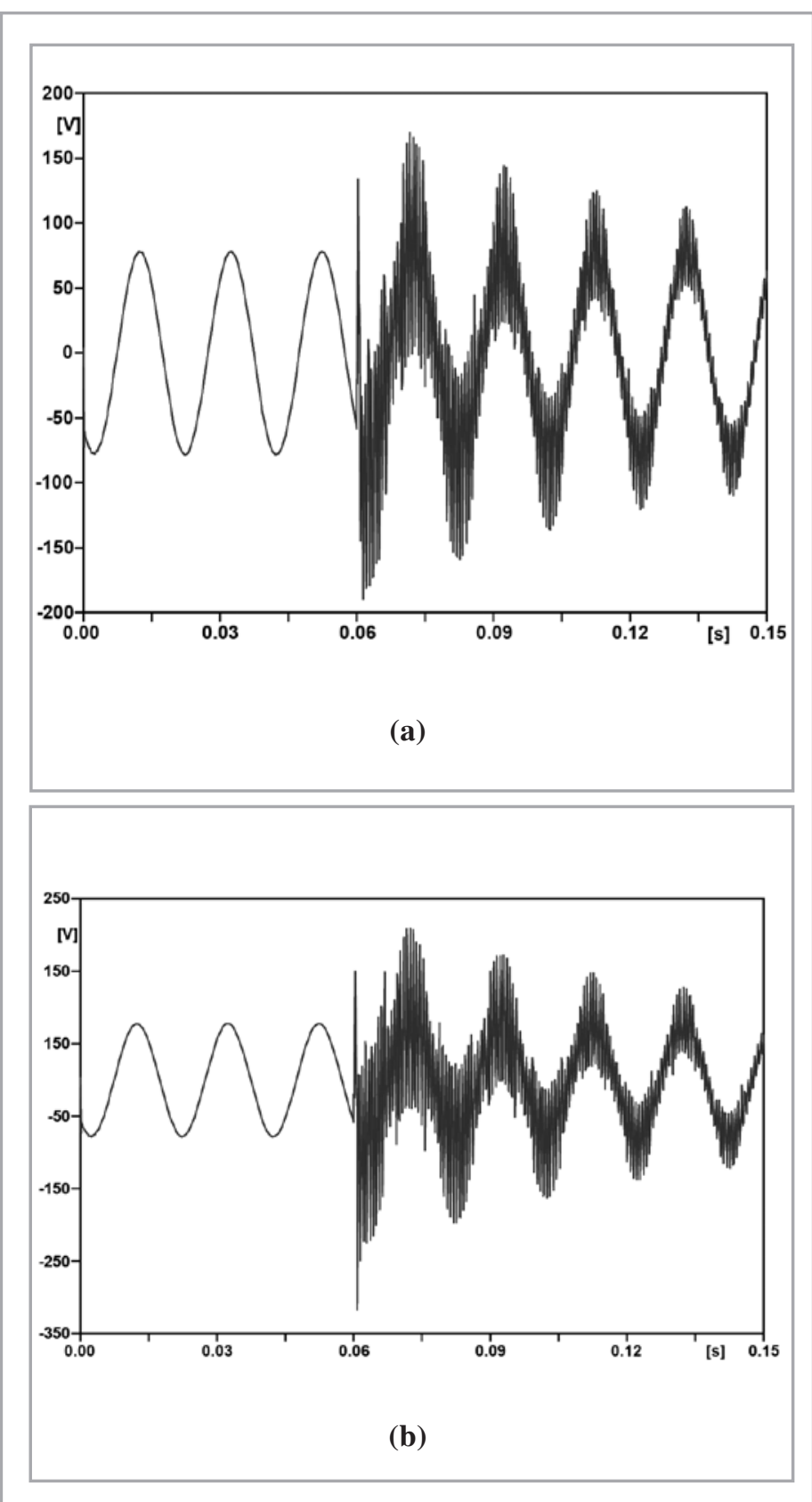

Figure 10 : CVT secondary output voltages for (a) Distance between lightning arrester and CVT $=3 m$, (b) Distance between lightning arrester and $C V T=10 \mathrm{~m}$

From Figures 10(a) and 10(b), it's obvious that, the CVT is subjected to more severe transient, as the distance between the lightning arrester and CVT increase. 


\subsection{CONCLUSIONS}

This paper presents the simulation results of digital-time domain studies conducted on a typical $132 \mathrm{kV}$ CVT model using ATP-EMTP software. It also includes a lightning case study on a typical power system configuration where the CVT is connected. The investigation concludes that:

- Fault occurring at voltage zero-crossing generate the worstcase CVT transient.

- The transient produced by CVTs with PFSC are much less than those produced by CVTs with AFSC.
- The greater the CVT's equivalent capacitance (sum of stack capacitance), the smaller the amplitude of the transient oscillations.

- Burden with high power factor or nearly resistive give better transient response.

- Lightning can cause ferroresonance oscillation, which may lead to CVT failure.

- The possibility of CVT failure will increase as the distance between the CVT and lightning arrester increase. This is because that will cause voltage overstress to take place at the CVT secondary side.

\section{REFERENCES}

[1] M.R. Iravani, X. Wang, I. Polishchuk, J. Ribeiro and A. Sarshar, "Digital time-domain investigation of transient behaviour of capacitor voltage transformer," IEEE Trans. on Power Delivery, Vol. 13, No. 2, April 1998, pp.123133.

[2] Dudurych, I.M.; Gallagher, T.J.; Corbett, J. and Escudero, M.V.; "EMTP analysis of the lightning performance of a HV transmission line" IEE Proceedings Generation, Transmission and Distribution, Volume 150, Issue 4, 14 July 2003 pp. $501-506$.

[3] Chowdhuri, P.; Anderson, J.G.; Chisholm, W.A.; Field, T.E.; Ishii, M.; Martinez, J.A.; Marz, M.B.; McDaniel, J.; McDermott, T.R.; Mousa, A.M.; Narita, T.; Nichols, D.K. and Short, T.A. "Parameters of lightning strokes: a review" IEEE Transactions on Power Delivery, Volume 20, Issue 1, Jan 2005 pp.346 - 358.

[4] Ghassemi, F.; Gale, P.F.; Clegg, B.; Cumming, T. and Coutts, C.; "Method to measure CVT transfer function" IEEE Transactions on Power Delivery, Volume 17, Issue 4, Oct. 2002 pp. $915-920$.

[5] Instrument Transformer - Part 5: Capacitor Voltage Transformer, IEC/PAS 60044-5.

[6] M. Sanaye-Pasand, R.Aghazadeh, "Capacitive Voltage Substations Ferroresonance Prevention using Power Electronic Devices," International Conference on Power System Transients - IPST 2003 in New Orleans, USA.

[7] Preecha Sakarung, Somchai Chatratana, "Application of PSCAD-EMTDC and Chaos Theory to Power System Ferroresonanace Analysis," International Conference on Power System Transients (IPST'05) in Montreal, Canada, June 19-23, 2005, Paper No. IPST05 - 227.

[8] Alessandro Villa R. and Zulay Romero C., "Failure Analysis of CVT from Substations EL Tablazo and Cuatricentenario up $400 \mathrm{kV}$," International Conference on Power System Transients (IPST'05) in Montreal, Canada, June 19-23, 2005, Paper No. IPST05 - 150.

[9] D. Fernandes Jr., W. L. A. Neves, J. C. A. Vasconcelos and M. V. Godoy, "Coupling Capacitor Voltage Transformer:
Laboratory Test and digital Simulations," International Conference on Power System Transients (IPST'05) in Montreal, Canada, June 19-23, 2005, Paper No. IPST05 - 076 .

[10] D. Fernandes Jr., W. L. A. Neves and J. C. A. Vasconcelos, "Coupling Capacitor Voltage Transformer Representation for Electromagnetic Transient Studies," International Conference on Power System Transients - IPST 2003 in New Orleans, USA. Paper No. IPST03 -142.

[11] Galvan, A.; Cooray, V. and "Analysis of lightning-induced voltages in a network of conductors using the ATP-EMTP program" 10th International Conference on (Conf. Publ. No. 445) Electromagnetic Compatibility, 1997. 1-3 Sept. 1997 pp. 153 - 157.

[12] Ghassemi, F.; Gale, P.F.; Clegg, B.; Cumming, T. and Coutts, C.; "Method to measure CVT transfer function" IEEE Transactions on Power Delivery, Volume 17, Issue 4, Oct. 2002 pp. $915-920$.

[13] Graovac, M.; Iravani, R. Xiaolin Wang and McTaggart, R.D.; "Fast ferroresonance suppression of coupling capacitor voltage transformers" IEEE Transactions on Power Delivery, Volume 18, Issue 1, Jan 2003 pp.158 $-163$.

[14] Ghassemi,F.;Gale,P.;Cumming,T.;Coutts,C.and "Harmonic voltage measurements using CVTs" IEEE Transactions on Power Delivery, Volume 20, Issue 1, Jan 2005 pp 443 $-449$.

[15] Tziouvaras, D.A.; McLaren, P.; Alexander, G.; Dawson, D.; Esztergalyos, J.; Fromen, C.; Glinkowski, M.; Hasenwinkle, I.; Kezunovic, M.; Kojovic, L.; Kotheimer, B.; Kuffel, R.; Nordstrom, J. and Zocholl, S.; "Mathematical models for current, voltage, and coupling capacitor voltage transformers" IEEE Transactions on Power Delivery, Volume 15, Issue 1, Jan. 2000 pp.62 - 72.

[16] Bayadi, A.; Harid, N. and Zehar, K.; "Dynamic surge arrester protection performance on high voltage systems using EMTP" 39th International Universities Power Engineering Conference, 2004. UPEC 2004. Volume 1, 6-8 Sept. 2004 pp. $118-122$. 
[17] Iravani, M.R.; Chaudhary, A.K.S.; Giesbrecht, W.J.; Hassan, I.E.; Keri, A.J.F.; Lee, K.C.; Martinez, J.A.; Morched, A.S.; Mork, B.A.; Parniani, M.; Sharshar, A.; Shirmohammadi, D.; Walling, R.A. and Woodford, D.A.; "Modeling and analysis guidelines for slow transients. III. The study of ferroresonance" IEEE Transactions on Power Delivery, Volume 15, Issue 1, Jan. 2000 pp.255 - 265.

[18] Mozaffari, S.; Sameti, M. and Soudack, A.C.; "Effect of initial conditions on chaotic ferroresonance in power transformers" IEE Proceedings-Generation, Transmission and Distribution, Volume 144, Issue 5, Sept. 1997 pp. 456 -460 .

[19] Chakravarthy, S.K. and Nayar, C.V.; "Ferroresonant oscillations in capacitor voltage transformers" IEE Proceedings Circuits, Devices and Systems, Volume 142, Issue 1, Feb. 1995 pp. $30-38$.

[20] Sommerville, W.; Gover, J.; Sanchez, R. and Bou, J.; "Modeling of capacitive and electromagnetic field shielding effects in a CVT" Proceedings Electrical Insulation Conference and Electrical Manufacturing Expo, 2005. 2326 Oct. 2005 pp. $378-382$.

[21] He, B.; Yiquan Li and Bo, Z.Q.; "An adaptive distance relay based on transient error estimation of CVT" IEEE Transactions on Power Delivery, Volume 21, Issue 4, Oct. 2006 pp. $1856-1861$.

[22] Ghassemi, F.; Merron, J.; Cole, D. and Gale, P.; "Effect of CVTs on power system monitoring and fault recording" Eighth IEE International Conference on Developments in Power System Protection, 2004. Volume 2, 5-8 April 2004 pp. $514-517$.

[23] Loxton, A.E. and Britten, A.C.; "The measurement and assessment of corona power losses on $400 \mathrm{kV}$ transmission lines" 6th Africon Conference in Africa, 2002. Volume 2, 2-4 Oct. 2002 pp.613 - 616

\section{PROFILES}

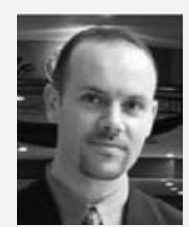

\section{ASSOCIATED PROF. DR SAAD MEKHILEF}

He received the B. Eng. degree in Electrical Engineering from University of Setif in 1994, and Master of Engineering science and $\mathrm{PhD}$ from University of Malaya 1998 and 2003 respectively. He is currently a Associate Professor at Department of Electrical Engineering; University of Malaya. Dr Saad is the author and co-author of more than 90 publications in international journals and proceedings. He is actively involved in industrial consultancy, for major corporations in the power electronics projects. His research interests include industrial electronics, power conversion techniques, control of power converters, renewable energy and energy efficiency

\section{MR. CHENG HOCK LIM}

He was born in Malaysia on June 30, 1981. He graduated from Universiti Tenaga Nasional with a Bachelor Degree in Electrical and Electronic Engineering (Hons) in 2004. Currently, He is pursuing his Master of Electrical Energy and Power System in University Malaya, Malaysia.

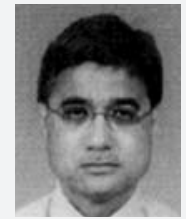

\section{DR AB. HALIM ABU BAKAR}

Dr Ab. Halim Abu Bakar was born in Malaysia on March 13, 1953. He graduated from Southampton University (England) with a B. Sc (Hons) in 1976, M.Eng and PhD from University Technology Malaysia in 1996 and 2003. His employment experience is with Tenaga Nasional Berhad (TNB) for the past 30 years. Among the posts that he had held were Chief Engineer Protection and General Manager (Asset Maintenance) Transmission Division. Presently he is with University of Malaya as a Senior Lecturer. He has presented papers in several conferences locally and abroad and involved in several conferences such as Vice-Chairman (Technical) CEPSI-1996, Committee Member CIGRE Symposium Malaysia 1999, Corresponding Member IEE $7^{\text {th }}$ international Conference on Development in Power System Protection Amsterdam 2001, committee Member $3^{\text {rd }}$ TNB technical Conference 2001 Malaysia and Special Reporter for CIGRE PARIS session 2004. He is responsible for establishing the RTDS in TNB for relay acceptance. 